\title{
METALLURGICAL AND PROCESS STRATEGY FOR THE PRODUCTION OF 700 MPA HOT ROLLED STRUCTURAL STEEL COIL*
}

Douglas Glenn Stalheim ${ }^{1}$

\begin{abstract}
Production of structural steel with a minimum yield strength of $700 \mathrm{Mpa}$ produced as hot rolled coil has become increasingly popular due to cost considerations when compared to quench and temper equivalent product. This grade when produced as hot rolled coil requires the use of microalloy precipitation strengthening mechanisms. This is typically a combination of niobium and titanium microalloys. While the metallurgical concept of structural steel precipitation strengthening mechanisms has been well researched and published, actual implementation into the production process can be very challenging. In addition to achieving a minimum yield strength of $700 \mathrm{Mpa}$, in many applications additional mechanical property attributes of formability as measured by hole expansion testing along with low temperature toughness properties are now required. Achieving a balance of all the mechanical properties in a stable and repeatable performance in production using microalloy precipitation strengthening mechanisms further increases the challenges. This paper will discuss the metallurgical/process strategies required to successfully produce $700 \mathrm{Mpa}$ minimum yield strength hot rolled structural steel coil. In addition, the role and goals of both niobium and titanium in this product design will be presented.
\end{abstract}

Keywords: Niobium; Titanium; Precipitation; Fine Grain.

1 Bachelor of Science in Metallurgical Engineering, President, DGS Metallurgical Solutions, Inc., Vancouver, WA USA. 


\section{INTRODUCTION}

Structural steel with $700 \mathrm{Mpa}$ minimum yield strength has been used in various applications such as transportation (automotive structural components, semi-trailer truck frames, etc.) and stationary/mobile crane booms, Figure 1.
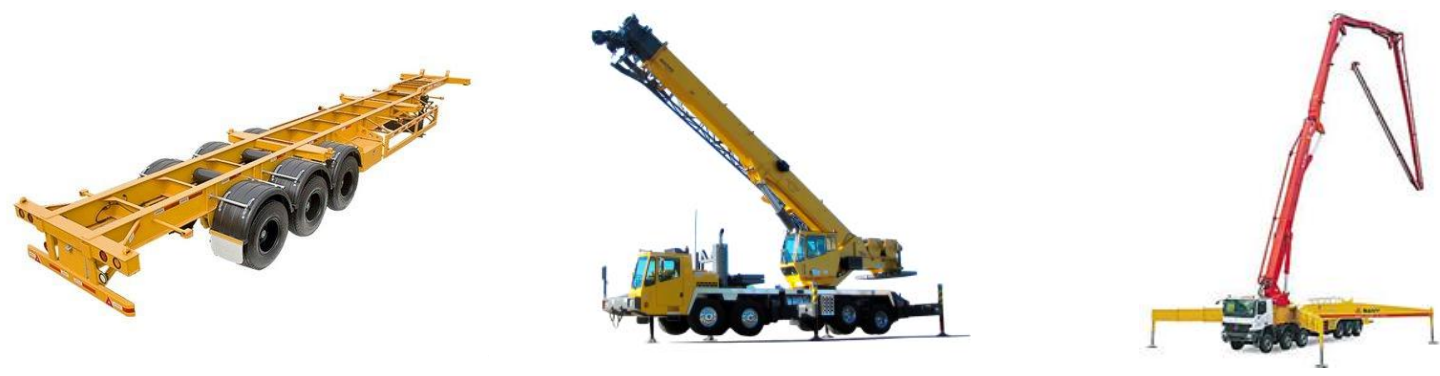

Figure 1. Example of uses of $700 \mathrm{Mpa}$ minimum yield strength structural steel

Typical thickness ranges for these applications is $4-12 \mathrm{~mm}$ with the bulk of the volume in the $6-10 \mathrm{~mm}$ range. Traditionally these applications are supplied with structural steel produced with bainitic/martensitic microstructures produced via quenching and tempering (QT). However, in the past several years to look at lower cost alternatives to QT steel, end users have been switching to hot rolled $\mathrm{Nb} / \mathrm{Ti}$ precipitation strengthened hot rolled coil. Now many hot rolled coil structural steel producers have developed or are in the process of developing 700 Mpa minimum yield strength steel for these applications.

Mechanical property attributes for these applications requires one or more of the following attributes:

- Yield Strength $>700 \mathrm{Mpa}$

- Tensile Strength $>750 \mathrm{Mpa}$

- Elongation $>10 \%$

- Low Temperature Toughness down to $-40{ }^{\circ} \mathrm{C}$

- Formability $<2 \times T-90^{\circ}$

To accomplish the strength level in a hot rolled structural steel coil, $\mathrm{Nb} / \mathrm{Ti}$ precipitation strengthening metallurgy is utilized. Niobium is used during hot rolling to create strength and ductility through austenite grain conditioning and titanium is used during post rolling cooling to create the final strength. However, this post rolling cooling titanium strengthening mechanism, while effective at increasing strength the TiC precipitates formed for strength can significantly impact the ductility performance of elongation, toughness and formability. In addition, achievement of the proper size, volume and distribution of TiC precipitates in the production process can be difficult. The combination of creating the proper balance of mechanical properties within the confines of various production equipment capabilities creates the major challenges in stable production of this grade.

\section{BASIC METALLURGICAL STRATEGY}

The basic metallurgical strategy for producing a hot rolled $700 \mathrm{Mpa}$ minimum yield strength consists of creating the proper microstructure, cross sectional grain size, 
solute strengthening elements and finally the proper precipitation strengthening mechanism. The basic three strengthening metallurgical building blocks can be seen in Figure 2 [1].

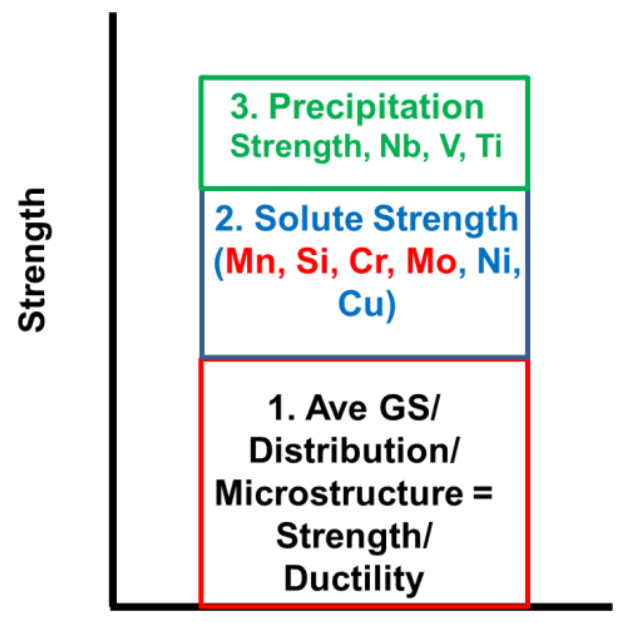

Figure 2. Three metallurgical building blocks for strength

Strength building block \#1 consisting of microstructure/grain size/distribution is where $\underline{A} \boldsymbol{L} \boldsymbol{L}$ the ductility properties will be developed and hence is the most important to properly optimize. This building block is where niobium microalloying technology is implemented. Strength building block \#2 consists of manganese and minor amounts of molybdenum and any natural residuals based on the melt source. Strength building block \#3 consists of post rolling TiC precipitation. Regardless of which microalloy is used for precipitation strengthening, there are two predominate precipitation strengthening mechanisms, interphase precipitation and random precipitation, Figure 3 [2].

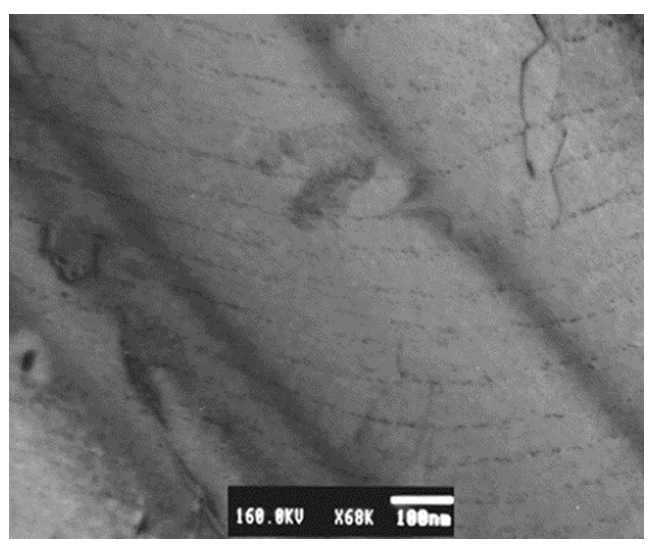

Interphase TiC precipitation. This is excellent for strength but poor for ductility/toughness.

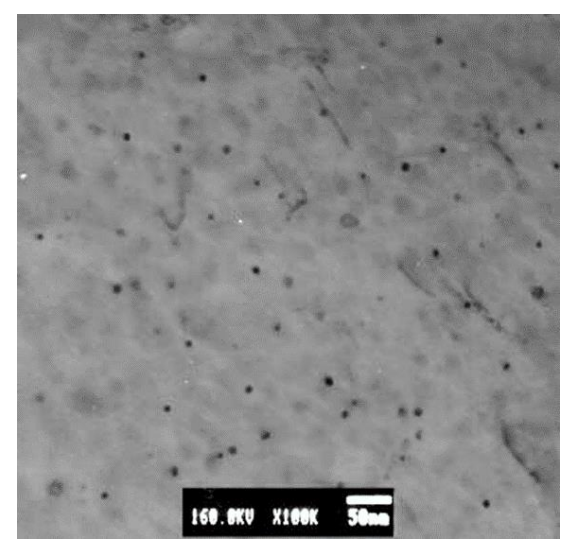

Random TiC precipitation. Will increase strength, but to a much lesser degree to that of interphase precipitation.

Figure 3. Example of $\mathrm{TiC}$ interphase and random precipitation strengthening mechanisms

Interphase precipitation is more efficient than random precipitation at creating strength and hence the desired mechanism, but it can be difficult to control. Regardless of which precipitation or combination of mechanisms is used it requires a significant amount of microalloy to still be solute during post rolling cooling and hence requires a significant starting volume during melting typically around $0.100 \%$ to 
create $700 \mathrm{Mpa}$ yield strength. As can be seen with either form of precipitation in Figure 3, the significant volume of precipitates and orientations can become detrimental to ductility properties. Bottom line precipitation strengthening mechanisms and excellent ductility are not synergistic with each other. Since a balance of strength and ductility (toughness, formability, etc.) is typically required and precipitation strengthening has a negative influence on ductility, this building block should be minimized and as much strength as possible should come from the first two strength building blocks. Key microstructural targets for optimum strength and ductility are as follows:

- Microstructure - 80-95\% polygonal ferrite, 5-20\% acicular ferrite (low carbon bainite)

- ASTM Average Ferrite Grain Size (Low Angle Grain Boundaries (LAGB $4^{\circ}$ ) and High Angle Grain Boundaries (HAGB 15)) - ASTM 12-13 (6 $\mu \mathrm{m}-4 \mu \mathrm{m})$ [3]

- Distribution of Grains - Accumulated Area Fraction of LAGB and HAGB $80 \%<$ $10 \mu \mathrm{m}$

The microstructure and grain size targets just mentioned can achieve yield strength up to $600 \mathrm{Mpa}$ hence requiring only an additional 100-150 Mpa of yield strength to come from TiC precipitation strengthening. An example of an optimum balance of the different strengthening components for $700 \mathrm{Mpa}$ yield strength structural coil can be seen in Figure 4 [4]. In Figure 4 the desired balance is on the right.

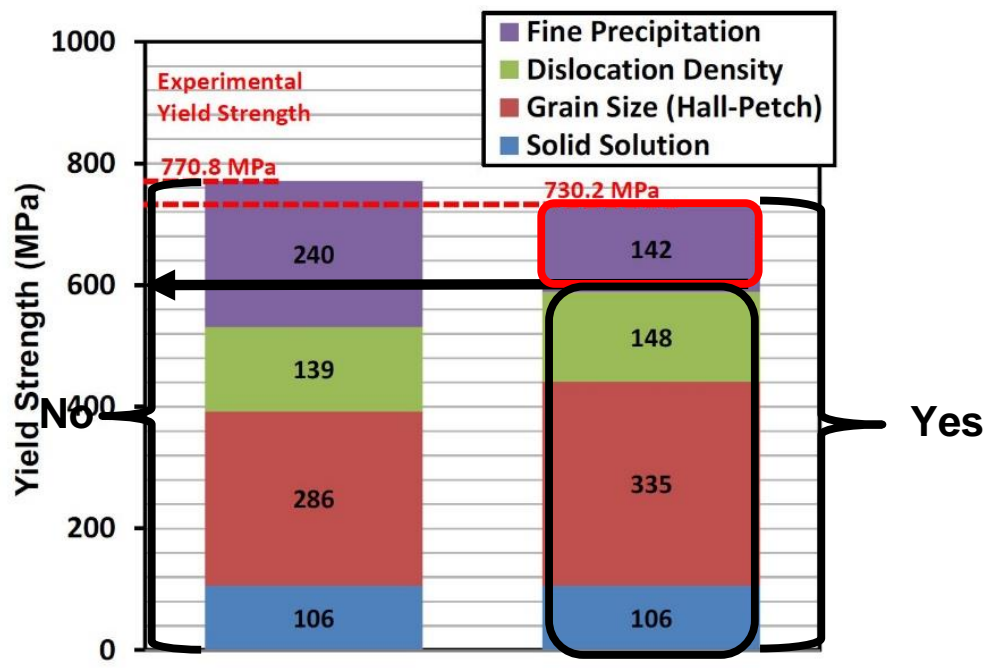

Figure 4. Example of achievement of up to $600 \mathrm{Mpa}$ yield strength without any precipitation strengthening. Final 700 Mpa yield strength then comes from 100-150 Mpa of post rolling cooling TiC precipitation, right side example is the desired approach to proper balance for strength and ductility.

To achieve the targeted cross sectional final microstructure/grain size/distribution requires the proper use of niobium microalloying technology during the rolling to create the austenite cross sectional grain size/distribution, proper alloy design to create the microstructural phase transformation and the creation of predominately fine interphase $\mathrm{TiC}$ along with minor amounts of random $\mathrm{TiC}$ precipitates during post rolling cooling for the final strength building block. 


\subsection{Cross Sectional Grain Size/Distribution}

Creating the very fine, homogenous cross sectional final ferrite grain size starts with producing a fine homogenous austenite cross sectional austenite grain size during rolling utilizing the proper amount of Type I Static Recrystallization and Type II Norecrystallization (pancaking) behavior [5]. For $700 \mathrm{Mpa}$ hot strip structural steel coil 50-60\% Type I Static Recrystallization and 65-80\% Type II No-recrystallization behavior is the desired target during hot rolling. Type III Partial Recrystallization behavior should be minimized as much as possible to preserve the homogeneity of the cross sectional grain size and optimize the ductility properties. This is accomplished with $\mathrm{Nb}$ metallurgy during rolling.

To determine the proper recrystallization stop temperature (RST) where Type II Norecrystallization starts during rolling the Tnr/RST equation developed by Bai [6] can be used, however it must be understood that titanium precipitates will also be formed starting in steelmaking/casting that can carry through and further contribute to that of the niobium in retarding recrystallization and hence actual data from the rolling mill for mean flow stress (MFS) analysis should be used to confirm exactly how much and which stand the Type II No-recrystallization behavior is generated. Figure $\mathbf{5}$ gives an actual example of $700 \mathrm{Mpa}$ yield strength hot rolled structural coil MFS analysis showing the various recrystallization behavior types [7].

Bai Tnr/RST Equartion $-\mathrm{Tnr}=\left(174 \log \left(\mathrm{Nb}^{\star}\left(\mathrm{C}+12 / 14^{\star} \mathrm{N}\right)\right)+1444\left({ }^{\circ} \mathrm{C}\right)\right)-75\left({ }^{\circ} \mathrm{C}\right)$

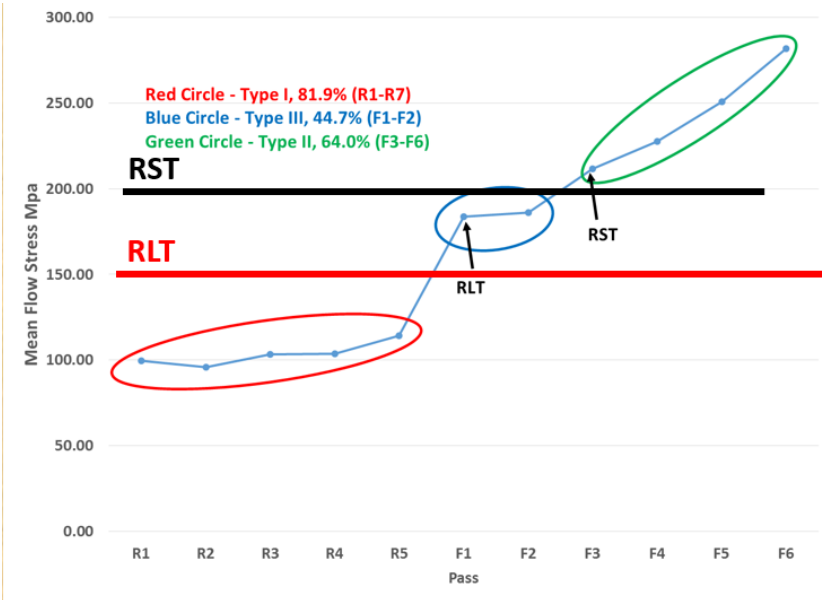

Figure 5. Example of actual 700 Mpa yield strength hot rolled coil MFS analysis for recrystallization behaviors

\subsection{Microstructural Phase Transformation}

The targeted microstructure is a polygonal ferrite with a small volume fraction of acicular ferrite. Figure 6 shows two illustrations of where acicular ferrite forms on the CCT phase transformation [8,9]. In this case, one of the roles of the small molybdenum addition makes is in shifting the pearlite transformation to allow for the acicular ferrite to form upon the desired cooling rate needed for TiC interphase precipitation to form in the laminar cooling (ACC) system [10]. 

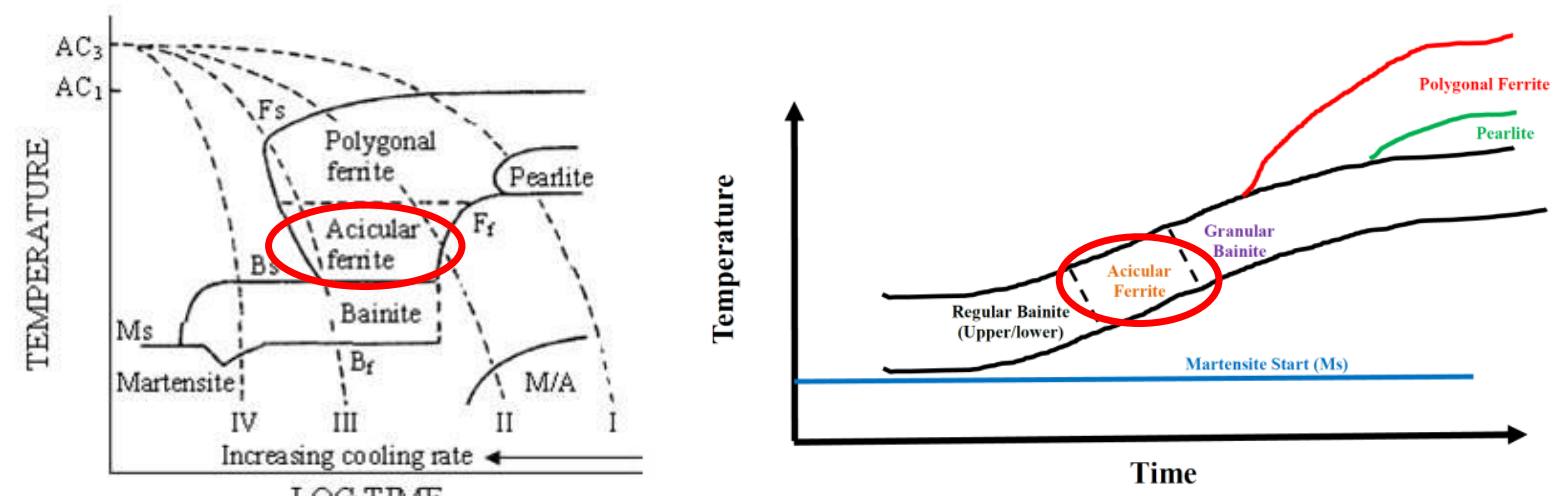

Figure 6. Illustration of acicular ferrite phase transformation during cooling

\subsection{TiC Post Rolling Precipitation}

Titanium precipitation strengthening mechanism which is the final key piece of the metallurgical strengthening seems to be relatively simple metallurgy as created in the laboratory, in production it is very challenging. Control of titanium metallurgy starts in steelmaking and continues all the way to final coiling. The goal is to have enough solute Ti remaining in the steel at the very end of the process in post rolling cooling to precipitate fine $\mathrm{TiC}$ through preferably interphase precipitation and then random $\mathrm{TiC}$ precipitation. But as can be seen in Figure 7, titanium starts precipitating very early on in steelmaking/casting and continues through the entire reheating and rolling process. How much titanium is still solute at the end of rolling for final precipitation is never truly known. This why it is preferred metallurgical strategy to achieve as much strength as possible through the microstructure, grain size and solute strengthening elements and then only require a small boost in strength from TiC precipitation. Relaying too much on $\mathrm{TiC}$ precipitation strength results in tremendous stability problems of strength properties over the course of daily/monthly production.

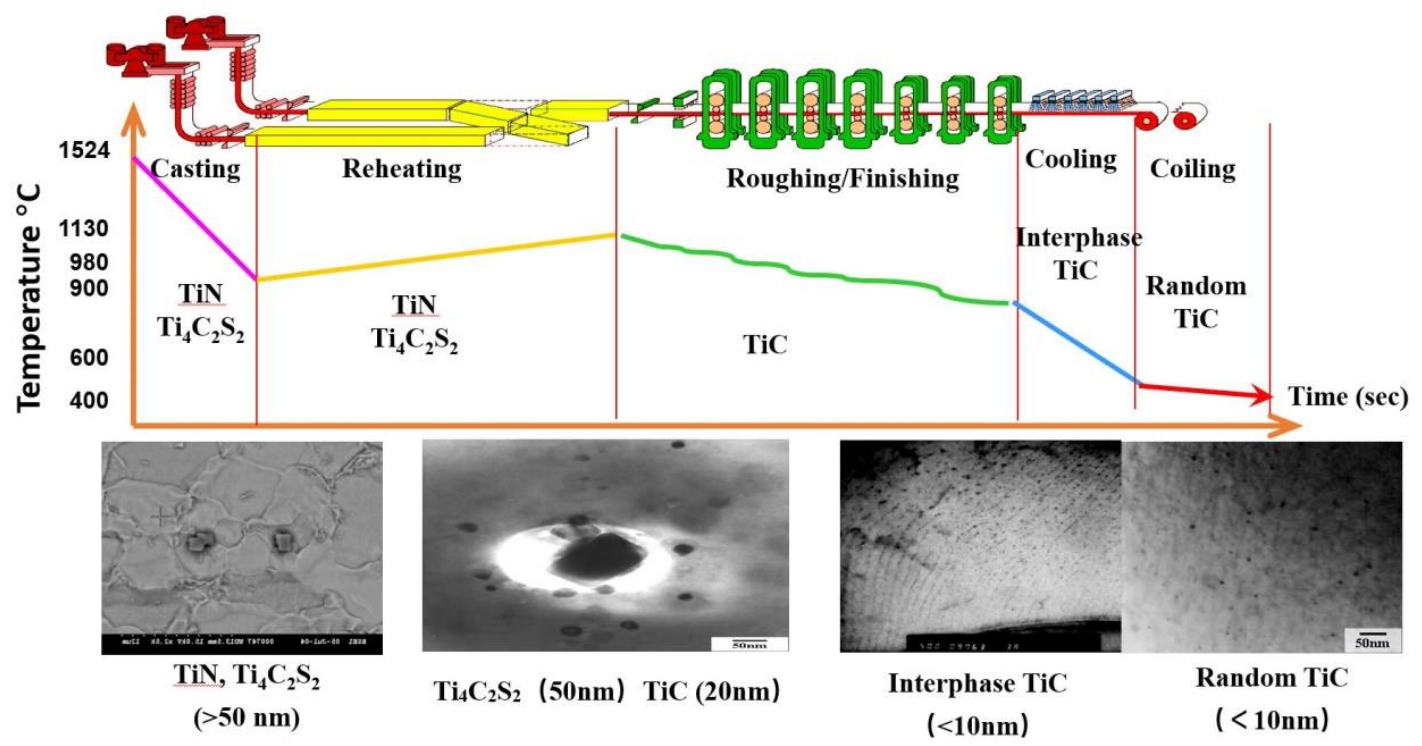

Figure 7. Illustration of Ti precipitate evolution from steelmaking to final coil cooling. The fine interphase and random TiC precipitation at the end of the process is what is desired for 700 Mpa yield strength structural steel. 
The size and volume fraction of the $\mathrm{TiC}$ precipitate is what contributes to the strengthening mechanism, Figure 8. TiC precipitate size should be as fine as possible, $<20 \mathrm{~nm}$ and preferably $<10 \mathrm{~nm}$.

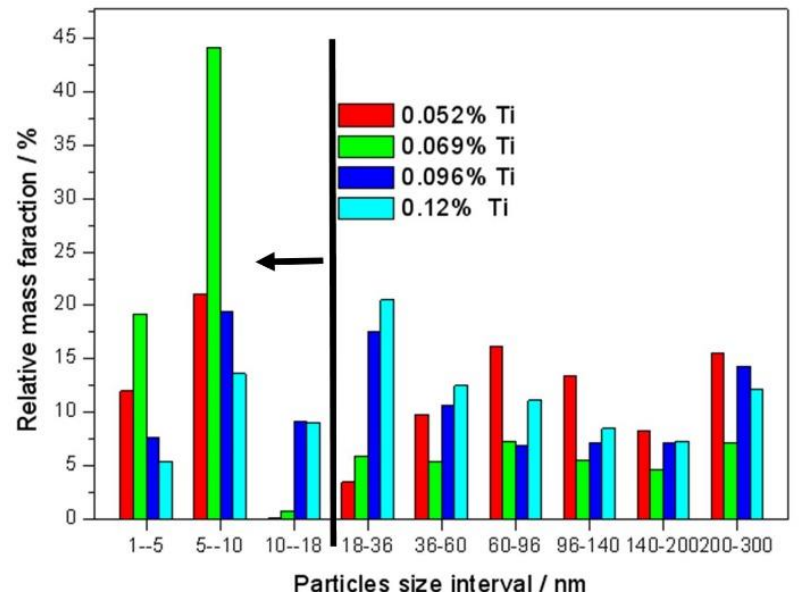

Figure 8. Various Ti precipitate sizes that can form during steelmaking/rolling/cooling. Note the black line/arrow is the desired size needed for efficient Ti precipitation strengthening.

Interphase $\mathrm{TiC}$ precipitation creates a higher volume fraction but the precipitates tend to be slightly larger, while random $\mathrm{TiC}$ precipitation creates less volume fraction but finer TiC precipitates. Figure 9 shows temperature/time where TiC interphase and random precipitation occur [11] and illustration of volume fraction/size relationship of each. The optimum $\mathrm{TiC}$ relationship would have the volume fraction created by interphase precipitation and the size/diameter created by random precipitation.

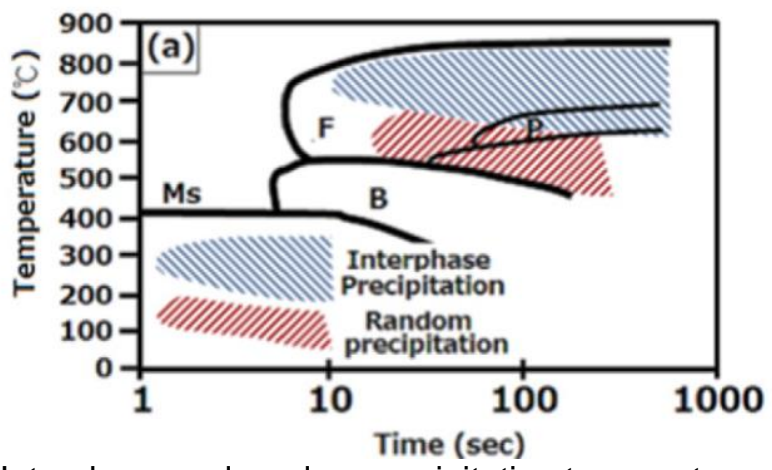

Interphase and random precipitation temperatures relative to CCT diagram

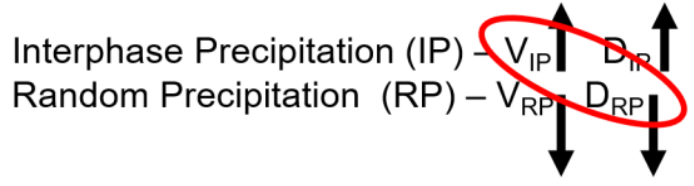

Illustration showing that a combination of

Figure 9. Example of interphase and random TiC precipitation temperature and relationship of volume fraction and diameter size of each.

To assist in controlling precipitate size a small molybdenum addition, $<0.20 \%$, can retard $\mathrm{TiC}$ precipitate growth during interphase precipitation [12].

\section{PRODUCTION DESIGN}

Optimized stable production of $700 \mathrm{Mpa}$ minimum yield strength hot rolled coil requires and understanding and control of key alloy/processing parameters in ALL areas of steel production including steelmaking/casting, rolling and post rolling 
cooling. Mistakes made in anyone of these areas will create stability issues in meeting the final required mechanical properties. As stated prior, the overall metallurgical concept is simple, but implementation, as many have found, in industrial production can be very challenging.

\subsection{Steelmaking/Casting}

Typical allow design for $700 \mathrm{Mpa}$ minimum yield strength hot rolled structural coil can be seen in Table 1.

Table 1. Typical alloy design

\begin{tabular}{|c|c|c|c|c|c|c|c|c|c|c|}
\hline C & $\mathbf{M n}^{1}$ & Si & $\mathbf{P}$ & $\mathrm{S}^{2}$ & $\mathrm{Mo}^{3}$ & $\mathrm{Nb}$ & $\mathrm{Ti}$ & Alt $^{4}$ & $\mathrm{~N}^{2}{ }^{2}$ & Total $\mathrm{O2}^{2}$ \\
\hline$<0.08$ & $\begin{array}{l}1.40- \\
2.00\end{array}$ & $<0.06$ & $<0.018$ & $<0.003$ & $<0.20$ & $\begin{array}{c}0.040- \\
0.065\end{array}$ & $\begin{array}{c}0.009- \\
0.130\end{array}$ & $<0.030 \%$ & $\begin{array}{c}\text { As low } \\
\text { as } \\
\text { possible, } \\
<60 \text { ppm }\end{array}$ & $\begin{array}{l}\text { As low as } \\
\text { possible, } \\
<20 \text { ppm } \\
\text { preferred }\end{array}$ \\
\hline
\end{tabular}

1. Mn should be adjusted based on residuals of $\mathrm{Cu}, \mathrm{Ni}$ and $\mathrm{Cr}$

2. $\mathrm{S}, \mathrm{N} 2$ and $\mathrm{O} 2$ need to be as low as possible to minimize undesirable Ti precipitate formation allowing for as much $\mathrm{Ti}$ as possible solute during cooling.

3. Mo to be added up to a maximum of $0.20 \%$ to assist with acicular ferrite formation and TiC precipitation size control during post rolling cooling.

4. Al should be as low as possible. Enough to properly deoxidize the steel and meet any specification requirement. Al inclusions are nucleation sites for complex TiNb precipitate formation, Figure 10.

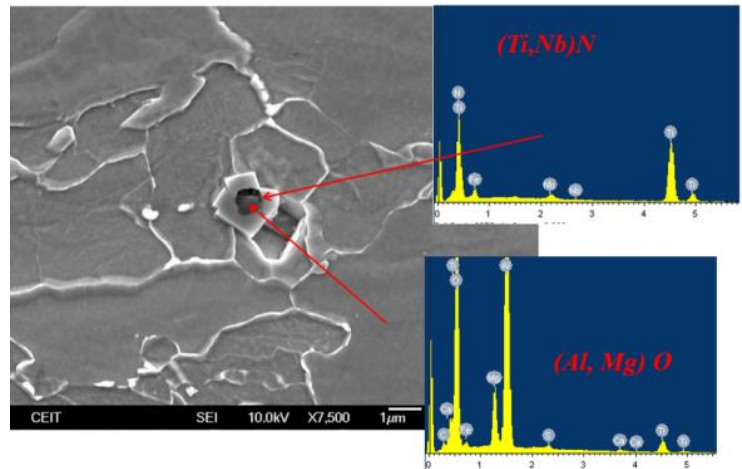

Figure 10. AlO inclusion creating nucleation site for undesirable complex (TiNb)N precipitate. Courtesy CEIT - San Sebastain, Spain.

Key processing points as noted in the chemistry is to try to optimize the solute $\mathrm{Ti}$ as much as possible in the process. Fast cooling during casting can help in minimize the Ti precipitate formation during casting. Low superheat, proper secondary cooling strategy, etc. are all important. In addition, as-cast centerline segregation mostly from the higher requirement for $\mathrm{Mn}$ maybe challenging a proper casting controls to minimize as-cast centerline alloy segregation should be implemented. In addition, the higher than normal Ti levels required can result in large, blocky Ti particles to form in the segregated centerline region.

\subsection{Rolling}

Slabs produced for this application should not be cold charged into the reheat furnace. Slabs should be stack cooled after casting until a surface temperature of $300-500{ }^{\circ} \mathrm{C}$ and then should be warmed charged into the reheat furnace. Initial heat up rate and corresponding thermal expansion/stresses, especially in the slabs 
corners can result in cracks to be formed in the reheat furnace, Figure 11. Typical slab reheating temperature is $1160-1200^{\circ} \mathrm{C}$.
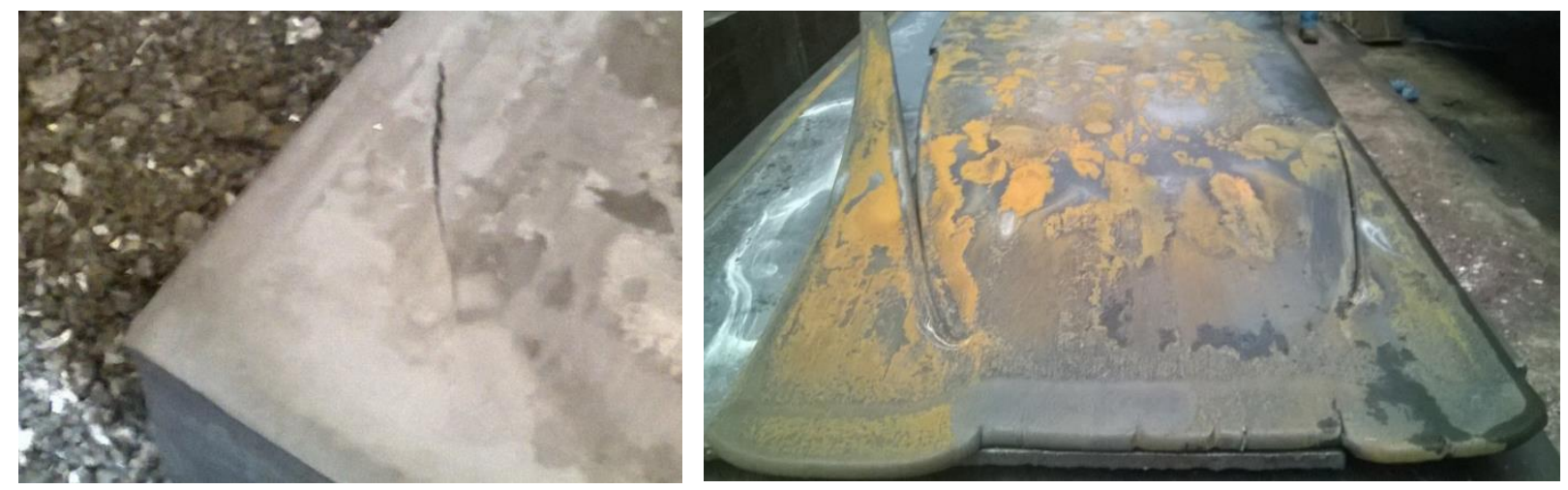

Figure 11. Example of slab cracking after reheating/roughing due to cold charging of the reheat furnace

The primary metallurgical goal of rolling is to create a very fine and homogenous cross sectional austenite grain size so that the final transformed ferrite grain size can be in the ASTM 12-14 range. To accomplish the desired austenite cross sectional grain size, proper control of Type I Static Recrystallization (50-60\% total deformation in roughing) and Type II No-recrystallization (pancaking) (65-80\% total deformation in finishing) behavior needs to be established. This is where $\mathrm{Nb}$ microalloying technology is utilized. The per pass reduction strategy for roughing and finishing needs to be optimized with key passes with sufficient deformation to condition the cross sectional austenite grain and create a robust strain induced $\mathrm{Nb}$ precipitation response. Figure 12 shows an optimized roughing and finishing hot strip per pass reduction schedule highlighting the critical metallurgical reduction passes for optimum final cross sectional austenite grain size.

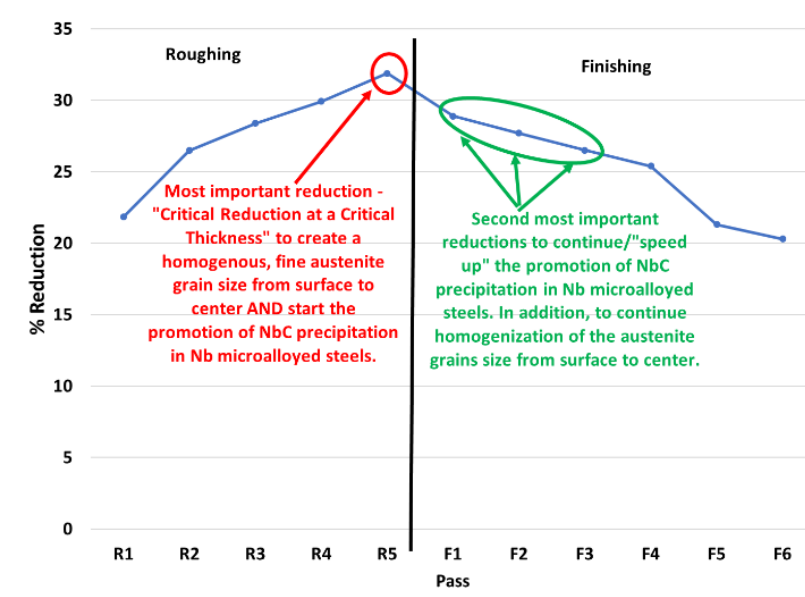

Figure 12. Example of optimized per pass reduction strategy/schedule

In addition, as previously mentioned mean flow stress analysis can help confirm if the proper recrystallization behaviors have been generated. Along with MFS analysis, practical microstructural models such as the MicroSim ${ }^{\circledR}$ model developed by CBMM/CEIT can be used to show the pass by pass austenite grain size/distribution evolution. Figure 13 shows an example of an actual $700 \mathrm{Mpa}$ chemistry/process 
design austenite grain size evolution modeled in the MicroSim ${ }^{\circledR}$ microstructural model. Note the fine and homogenous austenite grain size on the last pass and then the corresponding ferrite transformation grain size.

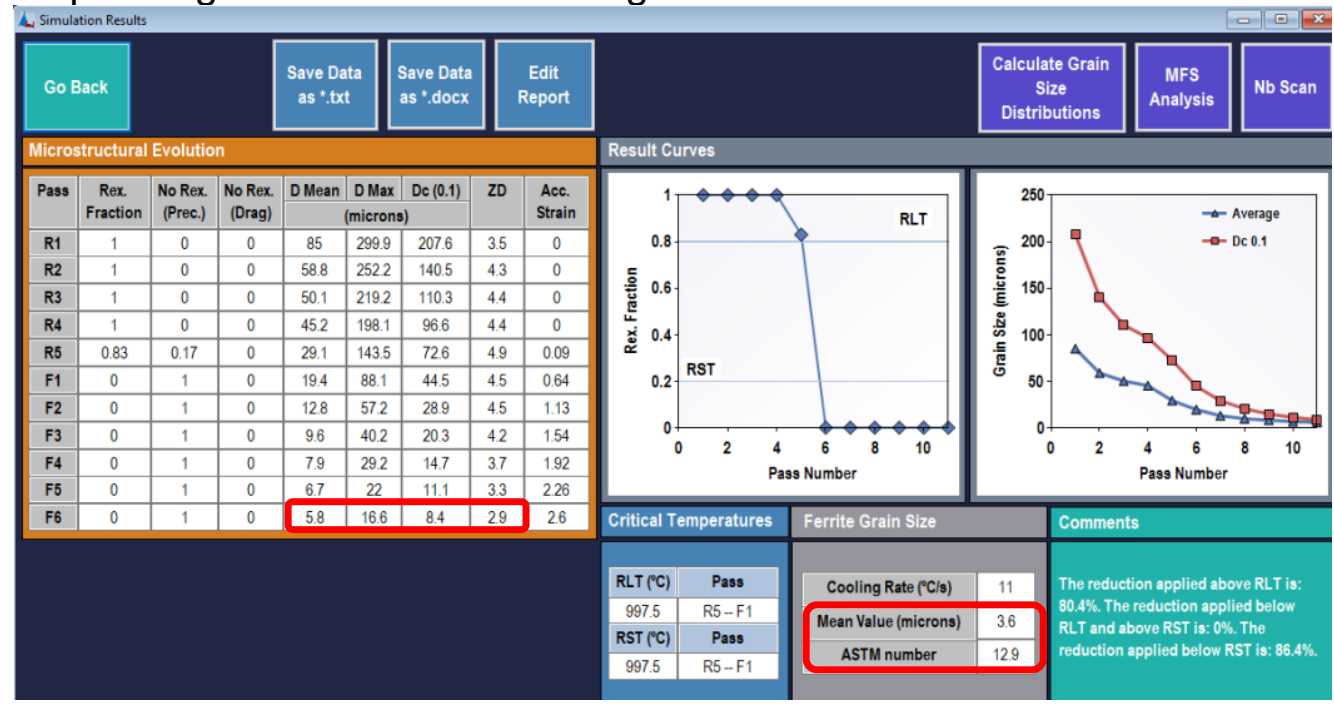

Figure 13. CBMM/CEIT MicroSim ${ }^{\circledR}$ microstructural model output for $700 \mathrm{Mpa}$ hot rolled structural coil. Note the final pass austenite average, maximum and $10 \%$ (Dc (0.1) maximum size along with a measure of the distribution (ZD value, which is the max grain size/average grain size) and the final ferrite grain size of $3.8 \mu \mathrm{m}$ (ASTM 12.9)

\subsection{Post Rolling Cooling}

The final piece of the metallurgical strategy for this grade and a very important one is the post rolling cooling. In this phase two very important metallurgical functions must be fulfilled:

1. Properly complete the austenite to ferrite transformation

2. Properly optimize the interphase/random TiC precipitation

While this seems simple it can be challenging as the temperature ranges and cooling rates required are counter to each other. In the case of the austenite to ferrite transformation the ferrite start transformation temperature (Ar3) can be between 730$760{ }^{\circ} \mathrm{C}$ and typically has a cooling rate in the $15-25^{\circ} \mathrm{C} / \mathrm{s}$ range. However, as can be seen in Figure 14, interphase TiC precipitation occurs in the $680-780{ }^{\circ} \mathrm{C}$ range and requires a slower cooling rate of $10-12{ }^{\circ} \mathrm{C} / \mathrm{s}$ and random $\mathrm{TiC}$ precipitation occurs in the $600-650^{\circ} \mathrm{C}$ range.

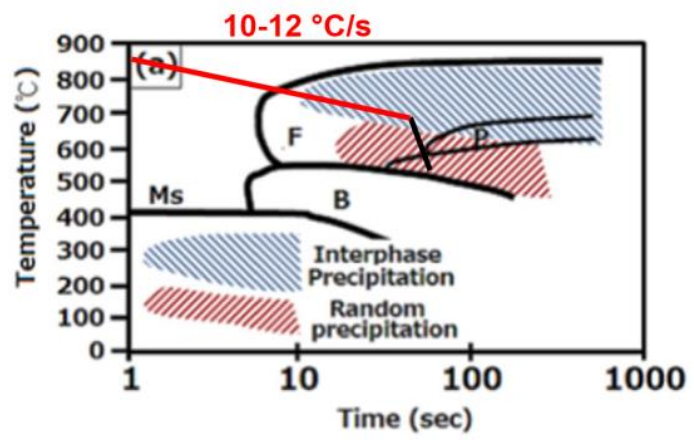

Figure 14. TiC interphase/random precipitation temperature range and desired cooling rate 
The challenges are if the cooling rate is too fast, microstructural phase/grain size transformation will be good, but the desired interphase TiC precipitation will be totally missed. To achieve the desired interphase TiC precipitation and any remaining available random TiC precipitation, a slower cooling rate is required and cooling stop temperature has to be in the $600-650 \mathrm{C}$ range. In doing, this the risk is that the austenite may not entirely transform during water cooling and then will continue to grow larger until finally transforming to ferrite during the final slow cooling of the coil resulting in very large ferrite grains (called "blown" grains), Figure 15.

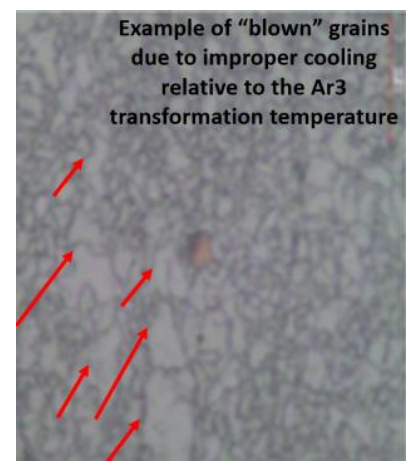

Figure 15. Example of large ferrite/"blown" grains due to improper austenite to ferrite transformation during coil cooling.

The overall strategy in post rolling cooling is to balance and achieve complete final microstructural formation, proper final ferrite grain size/distribution $\underline{A N D}$ achieve the desired TiC interphase precipitation for strength. This means once the strip enters the ACC water it must stay in the water at the proper cooling rate and achieve the proper cooling stop temperature to achieve all of the desired metallurgical attributes. Typical hot strip mills laminar (ACC) water control strategies utilizing trim banks, etc. cannot be used for this grade application. New control strategies, either manual or automatic through level 2 models, need to be developed for the laminar cooling systems.

If all the key metallurgical strategies are properly implemented and controlled in production an example of expected mechanical properly results can be seen in Table 2.

Table 2. Example of expected mechanical properties, $6 \mathrm{~mm} 700 \mathrm{Mpa}$ hot rolled coil

\begin{tabular}{|c|c|c|c|c|c|}
\hline $\begin{array}{c}\text { Average Yield } \\
\text { Strength } 0.2 \% \\
\text { offset (Mpa) }\end{array}$ & $\begin{array}{c}\text { Average } \\
\text { Tensile } \\
\text { Strength (Mpa) }\end{array}$ & $\begin{array}{l}\text { Average } \\
\text { Elongation } \\
\%(50 \mathrm{~mm})\end{array}$ & $\begin{array}{c}\text { Average } \\
\text { YTR }\end{array}$ & $\begin{array}{c}\text { Average } \\
\text { LCVN @ } \\
-40^{\circ} \mathrm{C}\end{array}$ & $\begin{array}{c}\text { Average } \\
\text { ASTM Grain } \\
\text { Size }\end{array}$ \\
\hline 718 & 778 & 24 & 0.92 & 102 & 13 \\
\hline
\end{tabular}

\section{CONCLUSION}

Production of high strength $700 \mathrm{Mpa}$ yield strength hot rolled coil in thicknesses form 4-12 $\mathrm{mm}$ has been increasing around the world as viable cost effective replacement for QT plate in various structural steel applications. This grade consists of a polygonal ferrite/acicular ferrite microstructure with a very fine/homogenous cross sectional ferrite grain size. Two different microalloying technologies are utilized to create the proper metallurgy. Niobium is used during hot rolling to properly refine the 
cross sectional austenite grains and titanium is used during post rolling cooling to create the final strength by fine $\mathrm{TiC}$ precipitation. Proper microstructure and $\mathrm{Nb}$ metallurgy employed during hot rolling can reach up to $600 \mathrm{Mpa}$ yield strength, requiring only another 100-150 Mpa of yield strength to be generated by the TiC precipitation strengthening mechanism. In addition to the strength, a very fine/homogenous cross sectional final ferrite grain size can result in optimum ductility properties for low temperature toughness and formability. While the metallurgical concept is relatively simple, implementation is very challenging on an industrial scale. However, with proper metallurgical and processing understanding stable successful production of hot strip coil can be realized.

Metallurgical and processing strategies have been presented in this paper with examples given. Proper use of mean flow stress analysis and practical metallurgical models such as the CBMM/CEIT MicroSim ${ }^{\circledR}$ model are useful tools to help optimize the cost and strategies for stable successful production.

\section{REFERENCES}

1 Stalheim DG, Bastos F, Microalloying Application in Structural Steels Hot Rolling of Microalloyed Steels, ABM Week 2016 Training Course, Rio de Janeiro, Brazil, 2016.

2 Kang, YL, "Microstructure and Precipitation of HSLA Steel by TSDR Process", 2015 International Symposium on TSDR Microalloyed Steels, Beijing, China, 2015.

3 Uranga, $\mathrm{P}$, et al., Optimized Cost Effective Production of Hot Rolled CSP Coils through Proper Austenite Conditioning, Proceedings AISTech 2017, Nashville, TN USA, 2017.

4 Stalheim, D., DGS Metallurgical Solutions, Inc. internal report 2016.

5 Stalheim, D., Understanding Recrystallization Behaviors for Optimization of Stable Mechanical Properties and Improved Yields, Proceedings from 2015 SEAISI

Conference \& Exhibition, Manila, Philippines, 2015.

6 Bai D, Bodnar R, Ward J, Dorricott J, Sanders S, Development of Discrete X80 Line Pipe Plate at SSAB Americas, Proceedings AIST International Plate Symposium, Winter Park, CO, USA, 2011.

7 Stalheim, D., DGS Recrystallization Behavior Analysis and Summary, DGS Metallurgical Solutions, Inc., Internal Training Presentation, 2015.

$8 \mathrm{Lu}$ J, et.al., "Microstructure Characterization and Strengthening Mechanisms of Microalloyed Steels", Proceedings of 7th ASME International Pipeline Conference, Calgary Canada, 2008.

9 Stalheim, D., DGS Continuous Cooling Transformation, DGS Metallurgical Solutions, Inc., Internal Training Presentation, 2015.

10 Heller, T., et.al., Effect of Alloying Elements on Microstructure and Mechanical Properties of Hot Rolled Multiphase Steels, Iron and Steelmaking, Vol. 32 No. 4, pg. 303-308, 2005.

11 Chen, $\mathrm{CY}$, et al., Microstructural characterization and strengthening behavior of nanometer sized carbide in Ti-Mo microalloyed steels during continuous cooling process, Materials Characterization, No. 114, pages 18-29, 2016.

12 Jang, $\mathrm{JH}$, et al., Interphase precipitation in Ti-Nb and Ti-Nb-Mo bearing steel, Materials and Technology, Vol. 29, No. 3, pages $309-313,2013$. 